\title{
Gender-specific differences in hypothalamus-pituitary-adrenal axis activity during childhood: a systematic review and meta-analysis
}

Bibian van der Voorn ${ }^{1 *}$ (D, Jonneke J. Hollanders ${ }^{1}$, Johannes C. F. Ket ${ }^{2}$, Joost Rotteveel ${ }^{1}$ and Martijn J. J. Finken ${ }^{1}$

\begin{abstract}
Background: Gender-specific differences in hypothalamus-pituitary-adrenal (HPA) axis activity have been postulated to emerge during puberty. We conducted a systematic review and meta-analysis to test the hypothesis that gender-specific differences in HPA axis activity are already present in childhood.

Methods: From inception to January 2016, PubMed and EMBASE.com were searched for studies that assessed non-stimulated cortisol in serum or saliva or cortisol in 24-h urine in healthy males and females aged $\leq 18$ years. Studies that conform with the Preferred Reporting Items for Systematic Reviews and Meta-Analysis (PRISMA) statement were reported. Standardized mean differences ( $95 \% \mathrm{Cls}$ ) were calculated and analyzed using fixed-effect meta-analysis stratified for age: $<8$ years (prepubertal) and $8-18$ years (peri-/postpubertal). For comparison, we ran the same analyses using random-effects models.

Results: Two independent assessors selected 413 out of 6158 records (7\%) for full-text screening, of which 79 articles were included. Of these, 58 (with data on 16,551 subjects) were included in the meta-analysis. Gender differences in cortisol metabolism differed per age group. Boys aged $<8$ years had $0.18(0.06 ; 0.30) \mathrm{nmol} / \mathrm{L}$ higher serum and $0.21(0.05 ; 0.37) \mathrm{nmol} / \mathrm{L}$ higher salivary cortisol levels, while between 8 and 18 years, boys had $0.34(0.28 ; 0.40)$ $\mathrm{nmol} / \mathrm{L}$ lower serum and $0.42(0.38 ; 0.47) \mathrm{nmol} / \mathrm{L}$ lower salivary cortisol levels. In $24-\mathrm{h}$ urine, cortisol was consistently higher in boys, being $0.34(0.05 ; 0.64)$ and $0.32(0.17 ; 0.47) \mu \mathrm{g} / 24 \mathrm{~h}$ higher in the $<8$ - and 8-18-year groups, respectively. However, gender-differences in serum cortisol $<8$ years and between 8 and 18 years were absent when using random-effects models.

Conclusions: Gender differences in cortisol metabolism are already present in childhood, with higher salivary cortisol in boys aged <8 years compared to girls. This pattern was reversed after the age of 8 years. In contrast, the gender-specific difference in cortisol production as assessed through 24-h urine did not change with age. Although differences were small, and analyses of gender differences in serum cortisol were inconclusive, they might contribute to gender-specific origins of health and disease.
\end{abstract}

Keywords: Glucocorticoid, Stress hormone, Infant, Pediatric, Sex characteristics

\footnotetext{
* Correspondence: b.vandervoorn@vumc.nl

'Department of Pediatric Endocrinology, VU University Medical Center,

Postbus 7057, 1007 MB Amsterdam, The Netherlands

Full list of author information is available at the end of the article
} 


\section{Background}

The hypothalamus-pituitary-adrenal (HPA) and hypothalamus-pituitary-gonadal (HPG) axes are closely connected. Animal studies demonstrated that corticotropin releasing hormone $(\mathrm{CRH})$ inhibits the HPG axis at all levels, while testosterone inhibits the HPA axis at the hypothalamic level. Additionally, estrogens stimulate the HPA axis at both the hypothalamic and adrenal levels. Moreover, CRH levels were dependent on the phase of the menstrual cycle, with the highest concentrations occurring during the follicular phase $[1,2]$.

Human studies suggested that estrogens decrease the hepatic A-ring reduction of cortisol, albeit not in the short term [3], and increase the production of corticosteroidbinding globulin (CBG), thereby affecting the bioavailability of cortisol $[1,4,5]$. The latter is being enhanced by the use of oral contraceptives. Furthermore, HPA-axis responses to acute psychological stress were different depending on the phase of the menstrual cycle $[2,4]$.

Due to an increase in sex steroid concentrations, gender differences in HPA axis activity have been postulated to emerge during puberty [6, 7]. However, more recent evidence suggests that gender differences in HPA axis activity are already present early in life $[1,8,9]$. Putative mediators of these prepubertal gender differences are the postnatal reproductive hormone surge, also known as mini-puberty [10], and sex-specific effects of styles in parental care, such as psychosocial stress reactivity to maternal over-controlling behavior [11]. However, physiological gender differences in cortisol concentrations during childhood have not been studied yet.

Therefore, the question was raised whether gender differences in unstimulated HPA axis activity emerge during puberty or whether they are already present earlier in life. Accordingly, we conducted a systematic review and meta-analysis with the hypothesis that gender-specific differences in unstimulated HPA axis activity are present in early life and are subsequently influenced by puberty.

\section{Methods}

\section{Search strategy}

From inception up to 14 January 2016, PubMed and EMBASE.com were searched (by BvdV and JCFK) for studies that reported non-stimulated cortisol in serum or saliva or cortisol in 24-h urine for healthy boys and girls aged $\leq 18$ years separately. Additional file 1 presents the full search strategy, which was based on the following index terms or free-text words: "cortisol" or "glucocorticoid", and "sex difference" or "sexual characteristics", and "child" or "adolescent". Studies in children with (psycho) pathology, on synthetic glucocorticoids, or with risk for abnormal HPA axis activity (e.g., a history of maltreatment) were excluded. An English language restriction was applied for abstracts of published articles. No restrictions for year of publication or study design, apart from reviews and case reports, were applied. The review protocol was based on the Preferred Reporting Items for Systematic Reviews and MetaAnalysis (PRISMA) statement.

\section{Data collection}

Two independent assessors (BvdV and JJH) screened 6158 titles and abstracts without consideration of outcomes. Studies were not assessed blindly. Disagreement between assessors was discussed until consensus was reached. When gender differences were analyzed without reporting on cortisol levels for boys and girls separately or when data were only presented in graphs, authors were requested for additional quantitative data. Data were stratified into two age groups: $<8$ years (prepubertal) and between 8 and 18 years (peri-/postpubertal). Ideally, stratification would have been based on pubertal staging according to Tanner. Unfortunately, only a minority of the included studies reported on the subjects' Tanner stages. Because pubertal onset before age 8 years is considered to be pathologic [12], we chose 8 years as cut off for stratification. When articles reported on serial cortisol measurements, we included only data on the youngest assessment age. When cortisol levels were reported prepubertally as well as peri-/postpubertally within the same individual, we included one sampling moment for each stratified group. When articles reported on the same study population, we included the article with the lowest bias risk. When articles reported on dynamic tests of HPA axis activity, we only included baseline cortisol. We only included the control subjects of case-control studies. If known, we excluded female subjects on oral contraceptives. When gender differences were described but not quantified, the articles were included in the descriptive analysis rather than the meta-analysis.

\section{Meta-analysis}

When necessary, we converted serum and salivary cortisol levels into nanomole per liter $(\mathrm{nmol} / \mathrm{L})$ and $24-\mathrm{h}$ urine cortisol levels into microgram per $24 \mathrm{~h}(\mu \mathrm{g} / 24 \mathrm{~h})$. When means \pm SDs were not reported, the SD was calculated based on the following assumptions: the $95 \% \mathrm{CI}$ is $3.92 \mathrm{SDs}$ wide $(2 \times 1.96)$; the inter-quartile range is $1.35 \mathrm{SDs}$ wide; the range is $4 \mathrm{SDs}$ wide; the $\mathrm{SD}$ is the $\mathrm{SE}$ multiplied by the square root of the sample size [13]. To assess parametricity, we assumed that a normal distribution extends no more than 2 SDs from the mean [14], i.e., when normally distributed, the mean minus 2 SDs should be $>0 \mathrm{nmol} / \mathrm{L}$. Data analyses were performed using Review Manager (RevMan) version 5.3.5, 2014. For each study, the standardized mean gender difference $(95 \%$ CI) in cortisol concentration was calculated by combining the SD with the sample size. Subsequently, fixedeffect meta-analyses were performed first, which assumes 
that the effect estimate of the group differences was fixed across studies. Second, the results of these analyses were compared with random-effects meta-analysis, which weigh studies of variable sample sizes more equally. We reported any source of bias from each included article conform the PRISMA statement and assessed selection, performance, detection, and other biases (Additional file 2). Bias was assessed as low, unclear, or high. A sensitivity analysis was done by excluding studies that had $\geq 1$ high bias risks. Heterogeneity of the data was assessed by the $I^{2}$ statistic, with significance defined as $I^{2}>50 \%$. Publication bias was assessed through funnel plots.

\section{Results}

Figure 1 shows the flowchart of the descriptive analysis and meta-analysis. Of the 6158 titles and abstracts, 414 (7\%) were eligible for full-text screening, from which 79 articles (19\%) were included. Thirty-one authors of articles with insufficient quantitative data were contacted, of whom 12 responded: six provided the necessary quantitative data, five did not have access to the raw data anymore, and one was not willing to participate. Two articles reported the cortisol production rate assessed through 24-h serum sampling, which hampered inclusion in the meta-analysis. The authors of 27 articles that only provided gender-specific data in figures were contacted, but could not be reached. Subsequently, these articles were excluded. Finally, 21 articles were included only in the descriptive analysis, and 58 articles (with data on 16,551 subjects) had sufficient data for inclusion in the meta-analysis.

\section{Description of included studies}

Studies were conducted in Europe $(n=36)$, North America $(n=37)$, Asia $(n=3)$, South America $(n=2)$, or Africa $(n=1)$ and were published between 1973 and 2016. Sample sizes ranged from 11 to 2824 subjects, with seven studies having a sample size $>500$ subjects. Study designs were as follows: randomized placebo-controlled $(n=2)$, prospective observational $(n=29)$, non-randomized intervention, i.e., stress tests $(n=15)$, cross-sectional $(n=16)$, longitudinal $(n=11)$, and case-control $(n=6)$. All studies that assessed serum or salivary cortisol used immunoassays, except for one that used high-performance liquid chromatography (HPLC). Studies that assessed 24-h urine cortisol used immunoassays $(n=4)$, gas chromatography-mass spectrometry $(n=3)$, HPLC $(n=1)$, and liquid chromatography-UV detection $(n=1)$. Twenty-two studies (28\%) did not collect morning samples, of which 11 did not report the time of collection and 11 described specifically that samples were collected in the afternoon. Additional file 3 presents the data extracted
6,923 records identified through database searching
3 additional articles identified through other sources

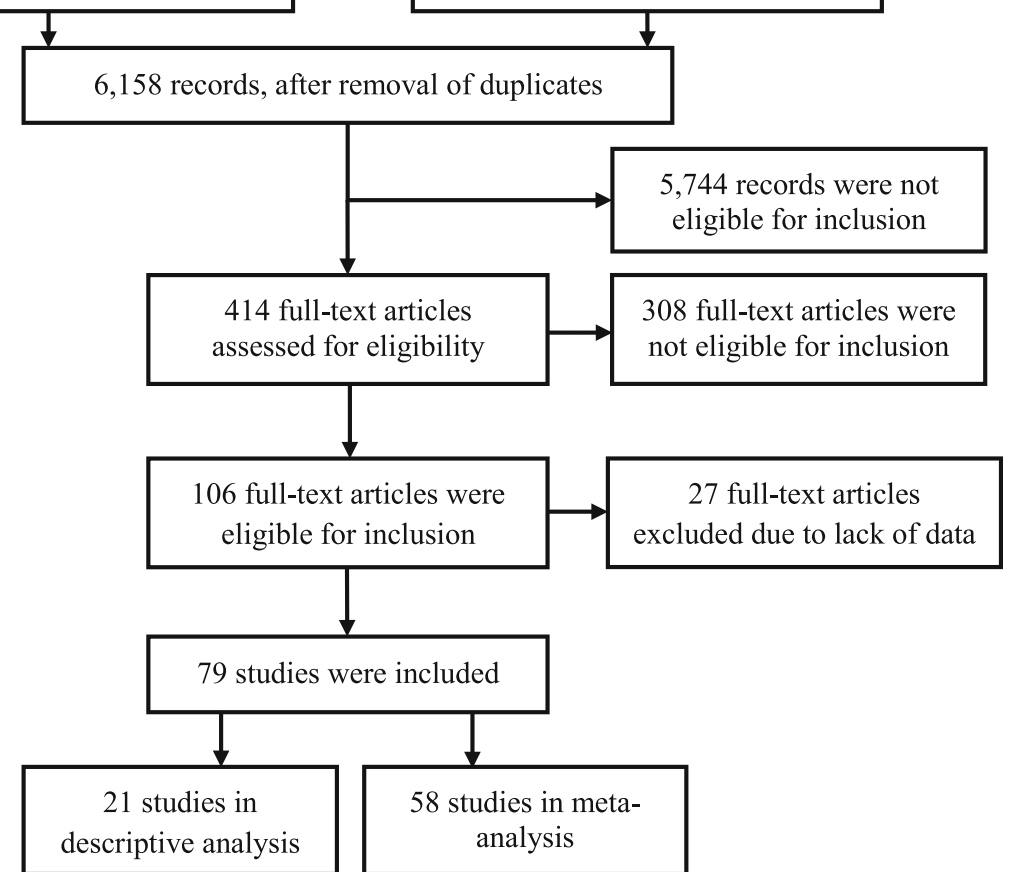

Fig. 1 This flow chart presents the different phases of the systematic review and meta-analysis, conform the PRISMA-statement. (www.prisma-statement.org) 
from the articles included in the meta-analysis. Three out of 21 studies (14\%) included in the descriptive analysis had no high bias risk (Table 1), while 16 out of 58 studies $(28 \%)$ included in the meta-analysis had no high bias risk (Fig. 2).

\section{Gender-specific differences \\ Descriptive analysis}

Table 1 summarizes the data on the 21 studies included in the descriptive analysis. The majority (90\%) of these studies reported no significant gender differences in cortisol levels. Before age 8 years, one study [15] found significantly lower salivary cortisol levels for boys at awakening. Between ages 8 and 18 years, one study [8] found significantly lower morning salivary cortisol levels in boys.

\section{Meta-analysis}

Nine articles (16\%) did not report mean and SD values, which were therefore calculated. Figure 3 shows the results of the fixed-effect meta-analysis of serum and salivary cortisol. Compared to girls, boys $<8$ years had $0.21(0.05 ; 0.37) \mathrm{nmol} / \mathrm{L}\left(P=0.01, I^{2}=48 \%\right)$ higher salivary and $0.18(0.06 ; 0.30) \mathrm{nmol} / \mathrm{L}\left(P<0.01, I^{2}=94 \%\right)$ higher serum cortisol levels. Between ages 8 and 18 years, boys had $0.42(0.38 ; 0.47) \mathrm{nmol} / \mathrm{L}\left(P<0.01, I^{2}=94 \%\right)$ lower salivary and $0.34(0.28 ; 0.40) \mathrm{nmol} / \mathrm{L}\left(P<0.01, I^{2}=97 \%\right)$ lower serum cortisol levels. In contrast, free cortisol in 24 -h urine was $0.34(0.05 ; 0.64) \mu \mathrm{g} / 24 \mathrm{~h}\left(P=0.02, I^{2}=\right.$ $55 \%)$ higher in boys aged $<8$ years and $0.32(0.17 ; 0.47)$ $\mu \mathrm{g} / 24 \mathrm{~h}\left(P<0.01, I^{2}=8 \%\right)$ higher in boys between ages 8 and 18 years (Fig. 4). The sensitivity analyses did not significantly change the results, although it decreased

Table 1 Summary of studies included in the descriptive analysis

\begin{tabular}{|c|c|c|c|c|c|c|c|}
\hline Group & First author (year) & $N(\%$ girls $)$ & Age (years) & Sample protocol & Assay & Result & Bias $^{a}$ \\
\hline \multirow[t]{5}{*}{ Saliva $<8$ years } & Klug (2000) [35] & $119(46 \%)$ & 0 & 3-point day curve & Immunoassay & No gender differences & 2 \\
\hline & Eiden (2015) [36] & $257(?)$ & 0.75 & $\begin{array}{l}\text { Laboratory temperament } \\
\text { assessment }\end{array}$ & Immunoassay & No gender differences & 3 \\
\hline & Plusquellec (2011) [37] & $466(?)$ & $1.6 \pm 0.1$ & Morning sample & Immunoassay & No gender differences & 2 \\
\hline & Spinrad (2009) [38] & $84(49 \%)$ & 4.5 & $\begin{array}{l}\text { Preschool laboratory } \\
\text { assessment }\end{array}$ & Immunoassay & No gender differences & 2 \\
\hline & Hatzinger (2007) [15] & $102(42 \%)$ & $4.9 \pm 0.4$ & CAR & Immunoassay & $\begin{array}{l}\text { Cortisol levels were lower } \\
\text { in boys at awakening } \\
(P<0.1)\end{array}$ & 1 \\
\hline \multirow[t]{5}{*}{ Saliva 8-18 years } & Safarzadeh (2005) [39] & $100(58 \%)$ & $6-14$ & Morning sample & Immunoassay & No gender differences & 1 \\
\hline & Isaksson (2015) [40] & $68(50 \%)$ & 9 & Morning sample & Immunoassay & No gender differences & 2 \\
\hline & Kjölhede (2014) [41] & $231(50 \%)$ & $9.5 \pm 1.5$ & Morning sample & Immunoassay & No gender differences & 1 \\
\hline & Vaillancourt (2008) [8] & $154(52 \%)$ & $12.3 \pm 0.8$ & $\begin{array}{l}\text { Six samples standardized } \\
\text { across time and day }\end{array}$ & Immunoassay & $\begin{array}{l}\text { On Saturday morning, } \\
\text { boys had significantly } \\
\text { lower morning levels. } \\
\text { On Monday and } \\
\text { Thursday, no significant } \\
\text { gender differences were } \\
\text { found. }\end{array}$ & 1 \\
\hline & Gunnar (2009) [42] & $82(49 \%)$ & $9-15$ & TSST & Immunoassay & No gender differences & 1 \\
\hline \multirow[t]{3}{*}{ Serum $<8$ years } & Fadalti (1999) [43] & $72(49 \%)$ & $0-2$ & Morning sample & Immunoassay & No gender differences & 0 \\
\hline & Ballerini (2010) [44] & $319(45 \%)$ & $0-5$ & Surplus serum & Immunoassay & No gender differences & 2 \\
\hline & Parker (1978) [45] & $106(43 \%)$ & $2-12$ & Morning sample & Immunoassay & No gender differences & 2 \\
\hline \multirow[t]{7}{*}{ Serum 8-18 years } & Kulasingam (2010) [46] & $419(?)$ & $0-15$ & Surplus serum & Immunoassay & No gender differences & 3 \\
\hline & Soldin (2005) [47] & $376(?)$ & $0-18$ & Surplus serum & Immunoassay & No gender differences & 1 \\
\hline & Karbasy (2015) [48] & $711(?)$ & $0-19$ & $?$ & Immunoassay & No gender differences & 1 \\
\hline & Fadalti (1999) [43] & $82(49 \%)$ & $6-18$ & Morning sample & Immunoassay & No gender differences & 0 \\
\hline & Barra (2015) [49] & $120(45 \%)$ & $12.4 \pm 3$ & Morning sample & Immunoassay & No gender differences & 1 \\
\hline & Chalew (1997) [50] & $15(73 \%)$ & $12.7 \pm 2.2$ & 24-h blood withdrawal & Immunoassay & No gender differences & 1 \\
\hline & Linder (1990) [51] & $82(58 \%)$ & $8-17$ & 24-h blood withdrawal & HPL & No gender differences. & 0 \\
\hline Urine $<8$ years & - & & & & & & \\
\hline Urine 8-18 years & Dorn (1996) [52] & $20(55 \%)$ & $15.2 \pm 1.1$ & 24-h urine sample & Immunoassay & No gender differences & 1 \\
\hline
\end{tabular}

${ }^{a}$ Number of high risks of bias out of four bias categories (selection, performance, detection, and other biases) 


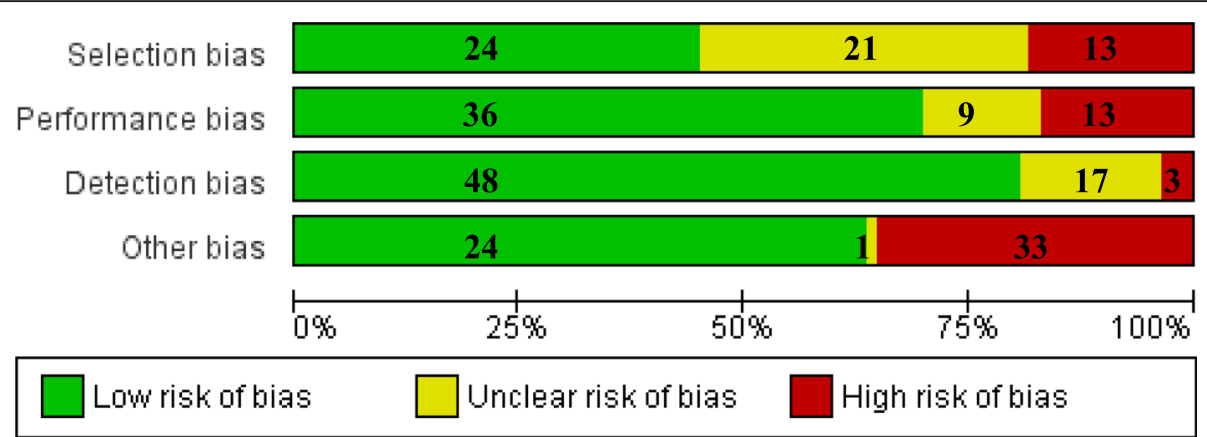

Fig. 2 Risk of bias graph presenting a summary of the judgements of the accessors concerning risk of bias across all studies included in the meta-analysis. Bias risk is presented as percentage of total studies $(n=58)$

the heterogeneity: boys $<8$ years had $0.40(0.11 ; 0.69)$ $\mathrm{nmol} / \mathrm{L}\left(P<0.01, I^{2}=55 \%\right)$ higher salivary, $0.45(0.30$; $0.61) \mathrm{nmol} / \mathrm{L}\left(P<0.01, I^{2}=94 \%\right)$ higher serum, and 0.28 $(-0.04 ; 0.61) \mu \mathrm{g} / 24 \mathrm{~h}\left(P=0.08, I^{2}=33 \%\right)$ higher $24-\mathrm{h}$ urine cortisol; boys $8-18$ years had $0.20(0.13 ; 0.26) \mathrm{nmol} / \mathrm{L}$ $\left(P<0.01, I^{2}=47 \%\right)$ lower salivary, $0.10(0.02 ; 0.18) \mathrm{nmol} /$ L $\left(P=0.01, I^{2}=33 \%\right)$ lower serum, and $0.24(0.02 ; 0.47)$ $\mu \mathrm{g} / 24 \mathrm{~h}\left(P=0.04, I^{2}=24 \%\right)$ higher 24 -h urine cortisol.

Additional file 4 shows the results of the comparison between fixed-effect vs. random-effects meta-analyses. When analyzed by the random-effects method, the effect estimates of serum cortisol $<8$ years and between 8 and 18 years became non-significant $(P=0.46$ and $P=0.62$, respectively). This also applied to salivary cortisol $<8$ years $(P=0.06)$ and urinary cortisol $<8$ years $(P=0.12)$, although trends in the same direction were observed.

Funnel plots showed no evidence of publication bias (Additional file 5).

\section{Discussion}

The results from this meta-analysis suggest that genderspecific differences in HPA axis activity are already present early in life. They also support previous observations which show that cortisol metabolism diverges between genders at pubertal age. Before age 8 years, cortisol in both serum and saliva was higher in boys compared to girls, at least in fixed-effect meta-analysis. These patterns were reversed after age 8 years. In contrast, gender differences in 24-h urine cortisol remained consistent with age, with higher cortisol levels in urine for boys before and after age 8 years (Additional file 6).

Total serum cortisol and free salivary cortisol reflect the balance between cortisol production and degradation, i.e., the bioavailability. Our meta-analysis suggests that puberty induces gender-specific changes in the bioavailability of cortisol, as reflected by similar changes in both total serum and free salivary cortisol levels, at least in fixedeffect models. Even though associations were absent for total serum cortisol in random-effect models, the change in free salivary cortisol could not be explained by an estrogen-induced increase in the production of CBG [4]. Moreover, the gender difference in cortisol in 24-hr urine (i.e., non-metabolized, free cortisol, representing cortisol production rate) remained consistent with age. Consequently, sex-hormone dependent effects on the hepatic metabolism of cortisol are more likely to explain our observations. Cortisol is metabolized reversibly by $11 \beta \mathrm{HSD} 2$, and irreversibly by $\alpha$ - and $\beta$-ring reductases and CYP3A. Animal studies showed a lower bioavailability of glucocorticoids in females due to decreased 11ßHSD1 [16-18] and relatively increased $11 \beta \mathrm{HSD} 2$ activity [18], as compared to males. In addition, previous observations in humans suggest that estrogens could alter hepatic cortisol metabolism through increased CYP3A activity $[19,20]$ and decreased A-ring reduction $[3,21]$. In contrast, sex-specificity in the activities of 11ßHSD isozymes is debated in humans $[3,21,22]$. Since analyses of gender-specific differences in total serum cortisol were inconclusive in randomeffects models (Additional file 4) and only one of the included studied had assessed CBG levels next to cortisol, we cannot exclude a gender-specific influence of CBG [4] on the serum cortisol level.

The HPA axis set point can be modified through an altered balance between mineralocorticoid and glucocorticoid receptor expression [23]. Animal studies have suggested that patterns in receptor expression develop in a gender-specific manner from birth onwards [24]. In humans, behavioral patterns that impact a child's stress vulnerability have been associated with gender-specific changes in cortisol levels from age 1.5 years onwards $[11,25]$. Therefore, even in our sample of normal children, gender-specific effects of stress exposure could be an explanation for our results [9].

Even subtle disturbances in HPA axis activity have been associated with cardiovascular disease and its risk factors [26-28]. Cardiovascular disease susceptibility is gender-specific [7, 29], which has been suggested to be due to gender differences in HPA axis activity, stress vulnerability, and responsivity [4, 30-32]. Early in life, developmental plasticity offers the child the capacity to 


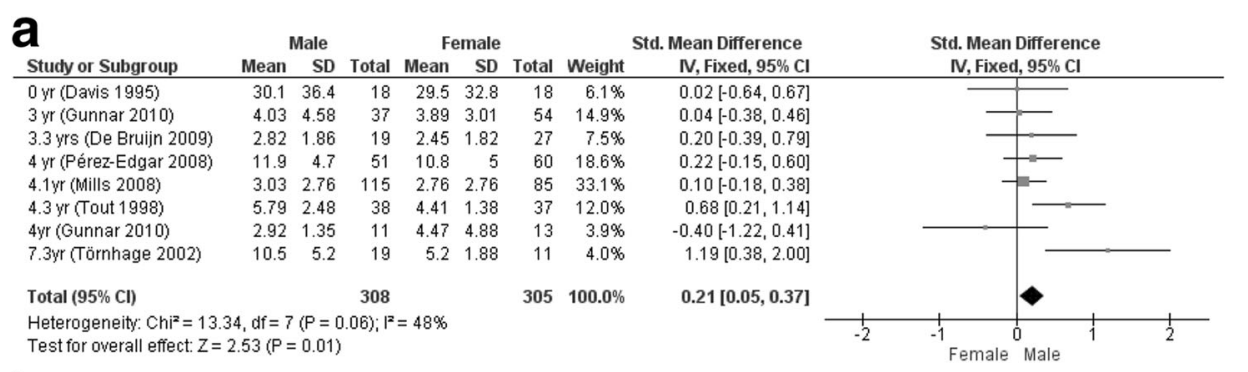

b

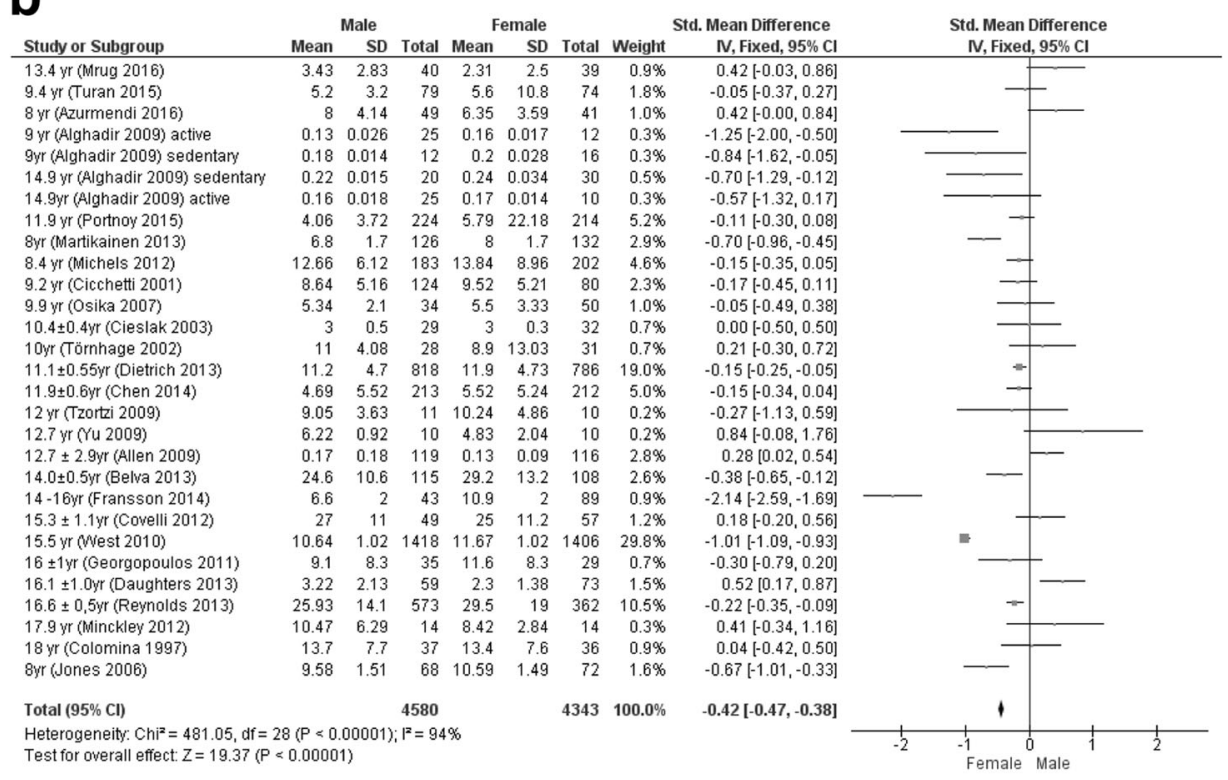

\section{C}
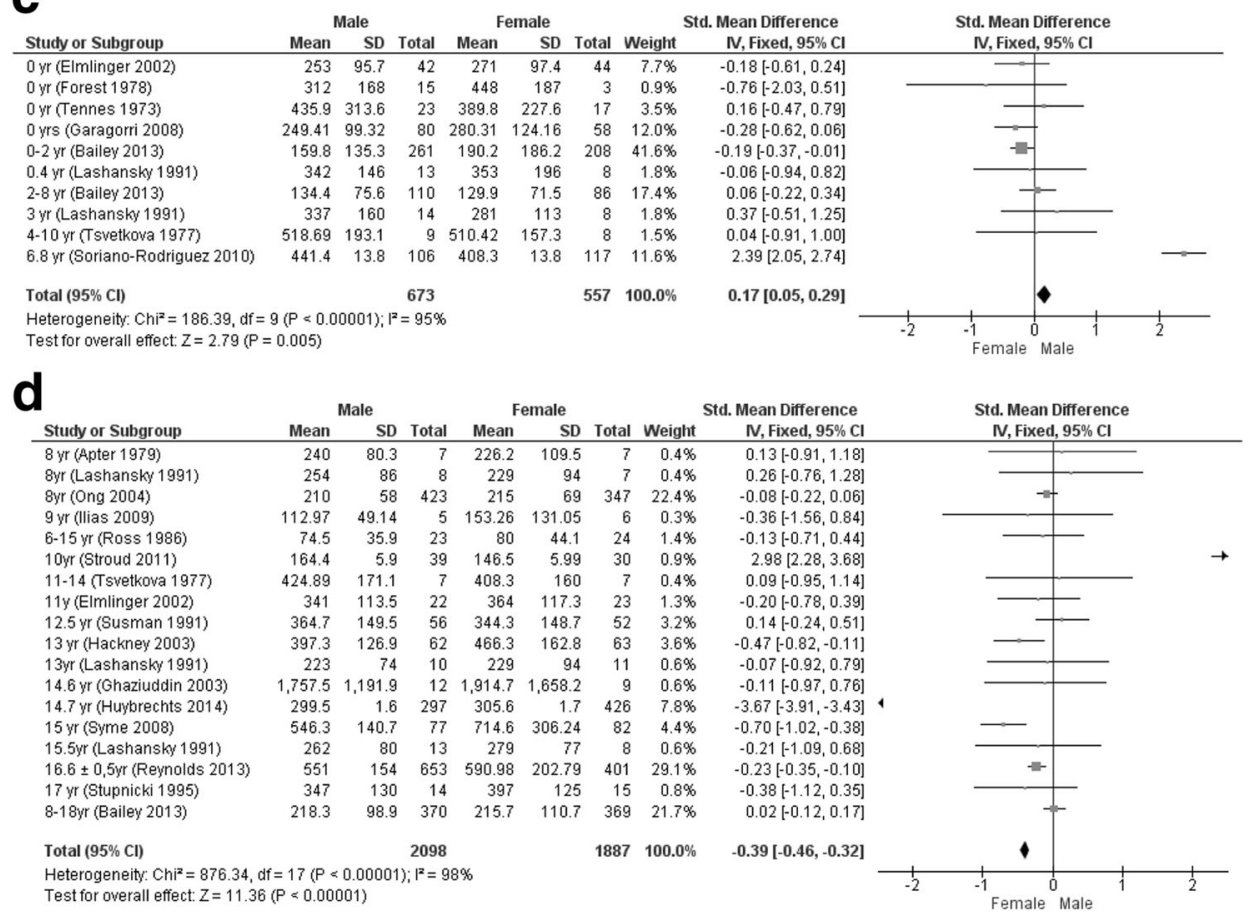

Fig. 3 Forest plots of gender differences per subgroup. a Salivary cortisol (nmol/L) $<8$ years of age. b Salivary cortisol (nmol/L) 8-18 years of age. c Serum cortisol $(\mathrm{nmol} / \mathrm{L})<8$ years of age. $\mathbf{d}$ Serum cortisol $(\mathrm{nmol} / \mathrm{L}) 8-18$ years of age 
a

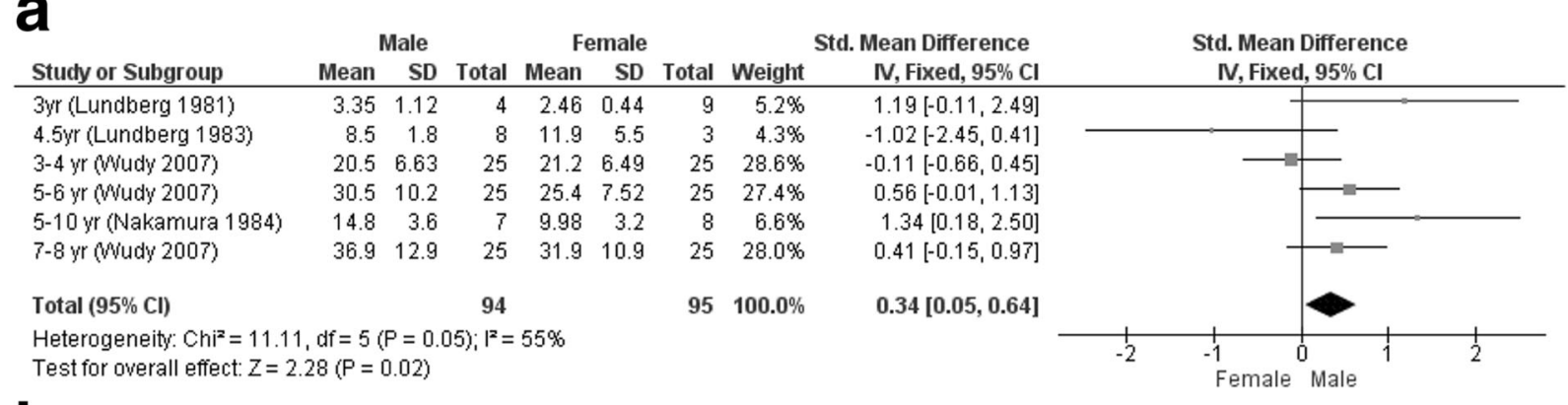

b

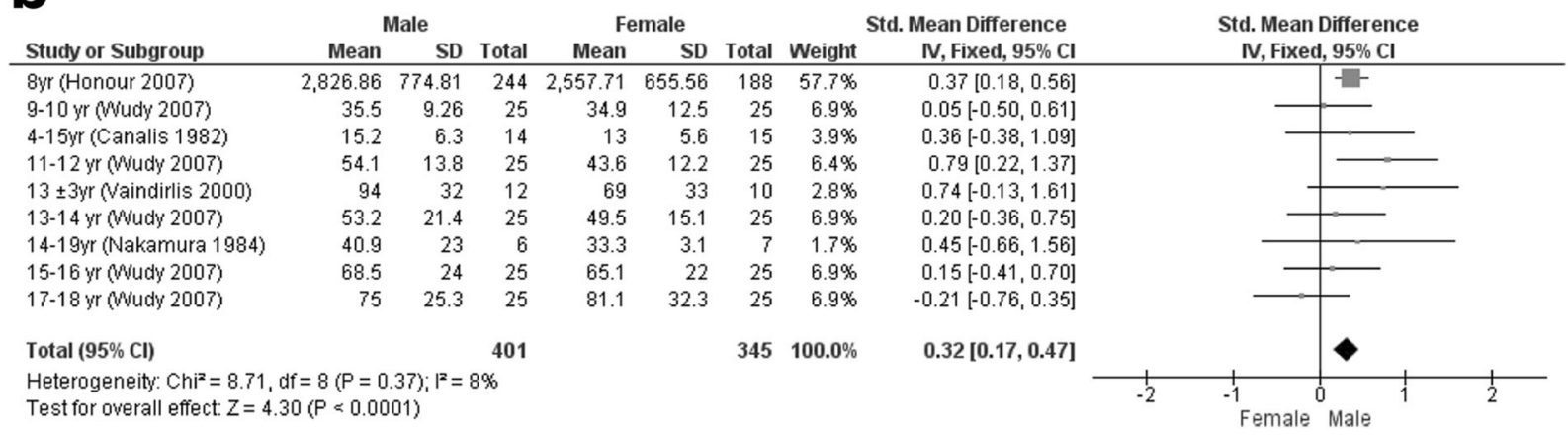

Fig. 4 Forest plots of gender differences per subgroup. a 24-h urine cortisol ( $\mu \mathrm{g} / 24 \mathrm{~h})<8$ years of age. b $24-\mathrm{h}$ urine cortisol ( $\mu \mathrm{g} / 24 \mathrm{~h}$ ) 8-18 years of age

change his HPA axis set point based on stress experiences $[9,33]$. This ability offers opportunities to withstand early-life challenges, but it has also been suggested to affect disease risk later in life. Accordingly, although the gender differences found in our study were small, these patterns might contribute to gender-specific origins of health and disease [9].

The major strength of this study is our systematic approach and the effort to contact all authors of eligible publications, enabling us to include the data on 16,551 healthy children. Moreover, articles with a lack of quantitative data were included in our descriptive analysis with the aim to be as complete as possible. The large sample size enabled us to perform a sensitivity analysis, which decreased the heterogeneity between studies. Furthermore, we accounted for this heterogeneity by calculating standardized mean differences, based on the intervention effects relative to the variability observed [13]. Additionally, we chose fixed-effect meta-analysis, because the studies with a large sample size were most likely conducted with greater methodological accuracy [13]. Fixed-effect meta-analysis has the advantage of increasing the impact of large studies on the effect estimate. For comparison, results of random-effects metaanalyses, which put more weight on studies with small sample sizes, were also included (Additional file 4).

A limitation of this study is that only a subset of studies $(16 \%)$ considered gender differences as the primary outcome. In addition, in 22 studies (28\%), samples were not collected specifically during mornings. Both could have led to a selection or performance bias, which we accounted for in our sensitivity analysis. Furthermore, 21 articles with data on 3985 subjects could not be included in the meta-analysis due to lack of gender-stratified quantitative data, while most of these articles reported no significant gender differences. However, funnel plots of the articles included in the meta-analysis were not suggestive of publication bias. Instead, the plots seem to indicate that most articles reported on the nonexistence of gender differences, which might be a result of the common idea that gender differences are nonexistent at this early age. Nonetheless, our meta-analysis shows that significant gender differences are already present early in life. Another limitation is that almost all studies that reported on salivary or serum cortisol used immunoassays. Due to its superior specificity, liquid chromatography-tandem mass spectrometry is the method of choice for steroid hormone analysis [34]. Furthermore, we stratified studies based on the mean age or age range of the study group. Since study samples differed in age range, we have probably included some subjects $<8$ years of age in the 8-18-year groups, and vice versa. An overview of the age ranges of studies included in the meta-analysis is presented in Additional file 6. Moreover, only a minority of the included studies assessed Tanner's pubertal staging. Therefore, we were unable to address the question at which maturational stage the direction of the gender-specific dimorphism in cortisol changes. 


\section{Conclusions}

In conclusion, gender differences in HPA axis activity are present early in life, with higher salivary cortisol concentrations in boys. A gender-specific evolution of cortisol metabolism is suggested to be induced by puberty, resulting in lower bioavailability of cortisol in boys. Although results from random-effects analyses were inconclusive for serum cortisol, the gender difference in cortisol production seems to be consistent between genders and age. Future research should take gender differences in HPA axis activity into account, regardless of age. Whether gender differences in stress-induced cortisol levels also exist is unknown and remains to be explored.

\section{Additional files}

Additional file 1: Search strategy (DOCX $21 \mathrm{~kb})$

Additional file 2: Risk of bias of studies included in the meta-analysis (DOCX $191 \mathrm{~kb}$ )

Additional file 3: Extracted data of studies included in the meta-analysis (DOCX $2550 \mathrm{~kb}$ )

Additional file 4: Comparison fixed-effect analysis vs. random-effects analysis. (DOCX 202 kb)

Additional file 5: Funnel plots. (DOCX $65 \mathrm{~kb}$ )

Additional file 6: Overview of age ranges of studies included in meta-analysis. (DOCX 20 kb)

\section{Abbreviations}

CBG: Corticosteroid-binding globulin; HPA axis: Hypothalamus-pituitaryadrenal axis; HPLC: High-performance liquid chromatography; PRISMA: Preferred Reporting Items for Systematic Reviews and Meta-Analysis; RevMan: Review manager

\section{Funding}

Nothing to declare

\section{Availability of data and materials}

The extracted data from included articles supporting the conclusions of this manuscript can be found in Table 1 and Additional files 2 and 3 .

\section{Author's contributions}

BvdV, JJH, JCFK, JR, and MF designed the review protocol. BvdV and JCFK conducted the search. BvdV and JJH screened the articles on eligibility and extracted the data. BvdV analyzed the data. BvdV, JJH, JR, and MF wrote the paper. BvdV had primary responsibility for the final content. All authors have read and approved the final manuscript.

\section{Competing interests}

The authors declare that they have no competing interests.

\section{Consent for publication}

Not applicable

Ethics approval and consent to participate

Not applicable

\section{Author details}

${ }^{1}$ Department of Pediatric Endocrinology, VU University Medical Center, Postbus 7057, 1007 MB Amsterdam, The Netherlands. ${ }^{2}$ Medical Library, Vrije Universiteit, De Boelelaan 1103, 1081 HV Amsterdam, The Netherlands.

Received: 20 August 2016 Accepted: 14 December 2016

Published online: 19 January 2017

\section{References}

1. Panagiotakopoulos L, Neigh GN. Development of the HPA axis: where and when do sex differences manifest? Front Neuroendocrin. 2014;35:285-302.

2. Bourke $\mathrm{CH}$, Harrell CS, Neigh GN. Stress-induced sex differences: adaptations mediated by the glucocorticoid receptor. Horm Behav. 2012;62:210-8.

3. Finken MJJ, Andrews RC, Andrew R, Walker BR. Cortisol metabolism in healthy young adults: sexual dimorphism in activities of A-ring reductases, but not 11-hydroxysteroid dehydrogenases. J Clin Endocrinol Metab. 1999;84:3316-21.

4. Kajantie E, Phillips DIW. The effects of sex and hormonal status on the physiological response to acute psychosocial stress. Psychoneuroendocrinology. 2006;31:151-78.

5. Perogamvros I, Ray DW, Trainer PJ. Regulation of cortisol bioavailability-effects on hormone measurement and action. Nat Rev Endocrinol. 2012;8:717-27.

6. Wudy SA, Hartmann MF, Remer T. Sexual dimorphism in cortisol secretion starts after age 10 in healthy children: urinary cortisol metabolite excretion rates during growth. Am J Physiol Endocrinol Metab. 2007;293:E970-6.

7. McCormick CM, Mathews IZ. HPA function in adolescence: role of sex hormones in its regulation and the enduring consequences of exposure to stressors. Pharmacol Biochem Behav. 2007;86:220-33.

8. Vaillancourt T, Duku E, Decatanzaro D, Macmillan H, Muir C, Schmidt LA Variation in hypothalamic-pituitary-adrenal axis activity among bullied and non-bullied children. Aggress Behav. 2008:34:294-305.

9. Hanson MA, Gluckman PD. Early developmental conditioning of later health and disease: physiology or pathophysiology? Physiol Rev. 2014:94:1027-76.

10. Raivio T, Toppari J, Kaleva M, Virtanen H, Haavisto AM, Dunkel L, Jänne OA. Serum androgen bioactivity in cryptorchid and noncryptorchid boys during the postnatal reproductive hormone surge. J Clin Endocrinol Metab. 2003;88:2597-9

11. Martinez-Torteya C, Muzik M, Mcginnis EW, Rosenblum KL, Bocknek EL, Beeghly M, Decator D, Abelson JL. Longitudinal examination of infant baseline and reactivity cortisol from ages 7 to 16 months. Dev Psychobiol. 2015;57:356-64.

12. Dattani MT, Tziaferi $V$, Hindmarsh PC. Evaluation of disorderd puberty. In: Brook C, Clayton P, Brown R, editors. Brook's Clinical Pediatric Endocrinology. Sixthth ed. 2009. p. 213-38.

13. Higgins JPT, Green S (editors). Cochrane handbook for systematic reviews of interventions version 5.1.0 [updated March 2011]. The Cochrane Collaboration, 2011. Available from www.handbook.cochrane.org.

14. Altman DG, Bland JM. Detecting skewness from summary information. BMJ. 1996:313:1200

15. Hatzinger M, Brand S, Perren S, von Wyl A, von Klitzing K, Holsboer-Trachsler E. Hypothalamic-pituitary-adrenocortical (HPA) activity in kindergarten children: importance of gender and associations with behavioral/emotional difficulties. J Psychiatr Res. 2007;41:861-70.

16. Jamieson PM, Chapman KE, Seckl JR. Tissue- and temporal-specific regulation of 11 beta-hydroxysteroid dehydrogenase type 1 by glucocorticoids in vivo. J Steroid Biochem Mol Biol. 1999;68:245-50.

17. Albiston AL, Smith RE, Krozowski ZS. Sex- and tissue-specific regulation of 11 beta-hydroxysteroid dehydrogenase mRNA. Mol Cell Endocrinol. 1995:109:183-8.

18. Loizzo S, Vella S, Loizzo A, Fortuna A, Di Biase A, Salvati S, Frajese GV, Agrapart V, Ramirez Morales R, Spampinato S, Campana G, Capasso A Galietta G, Guarino I, Carta S, Carru C, Zinellu A, Ghirlanda G, Seghieri G, Renzi P, Franconi F. Sexual dimorphic evolution of metabolic programming in non-genetic non-alimentary mild metabolic syndrome model in mice depends on feed-back mechanisms integrity for pro-opiomelanocortinderived endogenous substances. Peptides. 2010;31:1598-605.

19. Wolbold R, Klein K, Burk O, Nüssler AK, Neuhaus P, Eichelbaum M, Schwab M, Zanger UM. Sex is a major determinant of CYP3A4 expression in human liver. Hepatology. 2003;38:978-88.

20. Hunt CM, Westerkam WR, Stave GM. Effect of age and gender on the activity of human hepatic CYP3A. Biochem Pharmacol. 1992:44:275-83.

21. Toogood AA, Taylor NF, Shalet SM, Monson JP. Sexual dimorphism of cortisol metabolism is maintained in elderly subjects and is not oestrogen dependent. Clin Endocrinol (Oxf). 2000;52:61-6.

22. Weaver JU, Taylor NF, Monson JP, Wood PJ, Kelly WF. Sexual dimorphism in 11 beta hydroxysteroid dehydrogenase activity and its relation to fat distribution and insulin sensitivity; a study in hypopituitary subjects. Clin Endocrinol (Oxf). 1998;49:13-20. 
23. De Kloet ER, Vreugdenhil E, Oitzl MS, LS MJ. Brain corticosteroid receptor balance in health and disease. Endocr Rev. 1998;19:269-301.

24. Slotkin TA, Seidler FJ, Wood CR, Lau C. Development of glucocorticoid receptor regulation in the rat forebrain: implications for adverse effects of glucocorticoids in preterm infants. Brain Res Bull. 2008;76:531-5.

25. Tout K, de Haan M, Campbell EK, Gunnar MR. Social behavior correlates of cortisol activity in child care: gender differences and time-of-day effects. Child Dev. 1998;69:1247-62.

26. Chanson P, Salenave S. Metabolic syndrome in Cushing's syndrome. Neuroendocrinology. 2010;92 Suppl 1:96-101.

27. Rosmond R, Björntorp P. The hypothalamic-pituitary-adrenal axis activity as a predictor of cardiovascular disease, type 2 diabetes and stroke. J Intern Med. 2000;247:188-97.

28. Watt GC, Harrap SB, Foy CJ, Holton DW, Edwards HV, Davidson HR, Connor JM, Lever AF, Fraser R. Abnormalities of glucocorticoid metabolism and the renin-angiotensin system: a four-corners approach to the identification of genetic determinants of blood pressure. J Hypertens. 1992;10:473-82.

29. Hassan-Smith ZK, Morgan SA, Sherlock M, Hughes B, Taylor AE, Lavery GG, Tomlinson JW, Stewart PM. Gender-specific differences in skeletal muscle 11ß- HSD1 expression across healthy aging. J Clin Endocrinol Metab. 2015;100:2673-81

30. Kudielka B, Buske-Kirschbaum A, Hellhammer D, Kirschbaum C. HPA axis responses to laboratory psychosocial stress in healthy elderly adults, younger adults, and children: impact of age and gender. Psychoneuroendocrinology. 2004;29:83-98.

31. Otte C, Hart S, Neylan TC, Marmar CR, Yaffe K, Mohr DC. A meta-analysis of cortisol response to challenge in human aging: importance of gender. Psychoneuroendocrinology. 2005;30:80-91.

32. Stoney C, Davis M, Matthews K. Sex differences in physiological responses to stress and in coronary heart disease: a causal link? Psychopathology. 1987:24:127-31.

33. Bosch NM, Riese H, Reijneveld SA, Bakker MP, Verhulst FC, Ormel J, Oldehinkel AJ. Timing matters: long term effects of adversities from prenatal period up to adolescence on adolescents' cortisol stress response. The TRAILS study. Psychoneuroendocrinology. 2012:37:1439-47.

34. Ackermans MT, Endert E. LC-MS/MS in endocrinology: what is the profit of the last 5 years? Bioanalysis. 2014;6:43-57.

35. Klug I, Dressendörfer R, Strasburger C, Kühl GP, Reiter HL, Reich A, Müller G, Meyer K, Kratzsch J, Kiess W. Cortisol and 17-hydroxyprogesterone levels in saliva of healthy neonates: normative data and relation to body mass index, arterial cord blood ph and time of sampling after birth. Biol Neonate. 2000;78:22-6.

36. Eiden R, Molnar D, Granger D, Colder C, Schuetze P, Huestis M. Prenatal tobacco exposure and infant stress reactivity: role of child sex and maternal behavior. Dev Psychobiol. 2015;57:212-25.

37. Plusquellec P, Ouellet-Morin I, Feng B, Pérusse D, Tremblay RE, Lupien SJ, Boivin M. Salivary cortisol levels are associated with resource control in a competitive situation in 19 month-old boys. Horm Behav. 2011;60:159-64.

38. Spinrad TL, Eisenberg N, Granger DA, Eggum ND, Sallquist J, Haugen RG, Kupfer A, Hofer C. Individual differences in preschoolers' salivary cortisol and alpha-amylase reactivity: relations to temperament and maladjustment. Horm Behav. 2009;56:133-9.

39. Safarzadeh $E$, Mostafavi F, Haghi A. Determination of salivary cortisol in healthy children and adolescents. Acta Med Iran. 2005;43:32-6.

40. Isaksson J, Nilsson KW, Lindblad F. The Pressure-Activation-Stress scale in relation to ADHD and cortisol. Eur Child Adolesc Psychiatry. 2015;24:153-61.

41. Kjölhede EA, Gustafsson PE, Gustafsson PA, Nelson N. Overweight and obese children have lower cortisol levels than normal weight children. Acta Paediatr. 2014;103:295-9.

42. Gunnar MR, Wewerka S, Frenn K, Long JD, Griggs C. Developmental changes in hypothalamus-pituitary-adrenal activity over the transition to adolescence: normative changes and associations with puberty. Dev Psychopathol. 2009;21:69-85.

43. Fadalti M, Petraglia F, Luisi S, Bernardi F, Casarosa E, Ferrari E, Luisi M, Saggese G, Genazzani AR, Bernasconi S. Changes of serum allopregnanolone levels in the first 2 years of life and during pubertal development. Pediatr Res. 1999:46:323-7

44. Ballerini MG, Chiesa A, Scaglia P, Gruñeiro-Papendieck L, Heinrich JJ, Ropelato MG. 17alpha-Hydroxyprogesterone and cortisol serum levels in neonates and young children: influence of age, gestational age, gender and methodological procedures. J Pediatr Endocrinol Metab. 2010;23:121-32.

45. Parker L, Sack J, Fisher D, Odell W. The adrenarche: prolactin, gonadotropins, adrenal androgens, and cortisol. J Clin Endocrinol Metab. 1978;46:396-401.

46. Kulasingam V, Jung BP, Blasutig IM, Baradaran S, Chan MK, Aytekin M, Colantonio DA, Adeli K. Pediatric reference intervals for 28 chemistries and immunoassays on the Roche cobas 6000 analyzer - a CALIPER pilot study. Clin Biochem. 2010;43:1045-50.

47. Soldin OP, Hoffman EG, Waring MA, Soldin SJ. Pediatric reference intervals for FSH, LH, estradiol, T3, free T3, cortisol, and growth hormone on the DPC IMMULITE 1000. Clin Chim Acta. 2005:355:205-10.

48. Karbasy K, Lin DCC, Stoianov A, Chan MK, Bevilacqua V, Chen Y, Adeli K. Pediatric reference value distributions and covariate-stratified reference intervals for 29 endocrine and special chemistry biomarkers on the Beckman Coulter Immunoassay Systems: a CALIPER study of healthy community children. Clin Chem Lab Med. 2016;54:643-57.

49. Barra CB, Silva IN, Maria T, Rodrigues B, Lane J, Santos S, Colosimo EA. Morning serum basal cortisol levels are affected by age and pubertal maturation in school-aged children and adolescents. Horm Res Paediatr. 2015;83:55-61.

50. Chalew SA, Nagel H, Burt D, Edwards C. The integrated concentration of cortisone is reduced in obese children. J Pediatr Endocrinol Metab. 1997;10:287-90.

51. Linder BL, Esteban NV, Yergey AL, Winterer JC, Loriaux DL, Cassorla F. Cortisol production rate in childhood and adolescence. J Pediatr. 1990;117:892-6.

52. Dorn LD, Burgess ES, Susman EJ, von Eye A, DeBellis MD, Gold PW, Chrousos GP. Response to oCRH in depressed and nondepressed adolescents: does gender make a difference? J Am Acad Child Adolesc Psychiatry. 1996;35:764-73.

\section{Submit your next manuscript to BioMed Central and we will help you at every step:}

- We accept pre-submission inquiries

- Our selector tool helps you to find the most relevant journal

- We provide round the clock customer support

- Convenient online submission

- Thorough peer review

- Inclusion in PubMed and all major indexing services

- Maximum visibility for your research

Submit your manuscript at www.biomedcentral.com/submit
) Biomed Central 